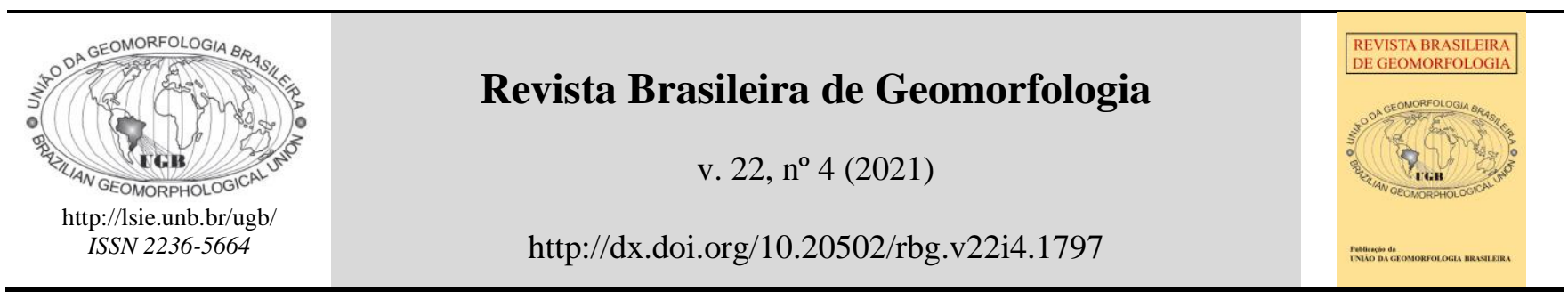

Artigo de Pesquisa

\title{
Integração de atributos topográficos na aplicação de regressões logísticas no mapeamento digital de solos situados em relevos suaves na região noroeste paranaense
}

\author{
Integration of topographic attributes in the application of logistic regressions \\ in digital soil mapping in low relief areas in the northwestern region of \\ Paraná
}

\author{
Alexei Nowatzki ${ }^{1}$, Leonardo José Cordeiro Santos ${ }^{2}$ \\ 1 Universidade Federal do Paraná (UFPR), Departamento de Geografia, Curitiba - PR, Brasil. nowatzki.a@gmail.com \\ ORCID: https://orcid.org/0000-0003-2634-5122 \\ 2 Universidade Federal do Paraná (UFPR), Departamento de Geografia, Curitiba - PR, Brasil. santos.ufpr@gmail.com. \\ ORCID: https://orcid.org/0000-0003-1165-6382
}

Recebido: 21/11/2019; Aceito: 21/05/2021; Publicado: 01/10/2021

\begin{abstract}
Resumo: A região noroeste do Paraná é composta por rochas sedimentares do grupo Caiuá, relevos pouco contrastados, clima tropical e ocorrência de Latossolos e Argissolos, que juntos representam mais de $50 \%$ dos solos existentes no território nacional. A associação solo-relevo nessa região dificulta o mapeamento pedológico tradicional, principalmente pela falta de parâmetros morfológicos em campo e em gabinete, que possam servir de base para delimitar essas classes de solos. Baseada na relação solo-relevo, o objetivo deste trabalho foi realizar um mapeamento digital de solos no baixo curso da bacia hidrográfica do rio Ivaí a partir da integração de atributos topográficos pelo método de regressões logísticas, buscando mapear as unidades de mapeamento Latossolo (UM-01) e Argissolo (UM-02). Os atributos selecionados para geração dos modelos foram: clinografia, índice de posição topográfica, índice de rugosidade do terreno, índice topográfico de umidade (modificado) e plano de curvatura. Os resultados indicaram uma maior distribuição da UM-01 no setor norte da bacia ao passo que a UM02 foi mais expressiva no setor sul. No total da área de estudo, a unidade de mapeamento referente aos Latossolos representa 45,3\%, enquanto dos Argissolos é de 54,7\%. Este trabalho demonstrou que mesmo em regiões com predomínio de relevos pouco contrastados é possível atingir resultados confiáveis utilizando o mapeamento digital de solos.
\end{abstract}

Palavras-chave: Mapeamento Digital de Solos; Regressões Logísticas; Noroeste do estado do Paraná.

\begin{abstract}
The northwestern region of Paraná is composed of sedimentary rocks of the Caiuá group, low relief areas, tropical climate and occurrence of Oxisols and Ultisols, which represent together more than $50 \%$ of the existing soils in the national territory. The soil-relief association in this region makes the traditional pedological mapping difficult, mainly due to the lack of field and office morphological parameters, which can serve as a basis to delimit these soil classes. Based on the soil-relief relationship, the objective of this work was to perform a digital soil mapping in the lower course of the Ivaí river basin from the integration of topographic attributes by the method of logistic regressions, seeking to map the unit map Oxisols (UM-01) and Ultisols (UM-02). The attributes selected to generate the models were: clinography, topographic position index, terrain roughness index, topographic wetness index (modified) and curvature plane. The results indicated a greater distribution of the UM-01 in the northern sector of the basin, while UM-02 was more expressive in the southern sector. In the total study area,
\end{abstract}


the Oxisols unit map represents $45.3 \%$, while the Ultisols is $54.7 \%$. This work has shown that even in regions with a predominance of low reliefs it is possible to achieve reliable results using digital soil mapping.

Keywords: Digital Soil Mapping; Logistic Regressions; Northwest of the state of Paraná.

\section{Introdução}

O mapeamento digital de solos (MDS), enquanto um ramo da Pedometria, possui enorme potencialidade na definição de unidades pedológicas de mapeamento e tem mostrado grande capacidade para a predição de solos. Esse método contribui no entendimento das relações solo-relevo e, consequentemente, mostra-se como uma ferramenta importante para identificar e mapear áreas com características pedológicas homogêneas (SIRTOLI et al., 2008; DALMOLIN; TEN CATEN, 2015). Lagacherie e Voltz (2000) destacam que os MDS são capazes de extrapolar os limites das classes de solos mapeadas digitalmente para áreas adjacentes e não mapeadas, no caso daquelas que apresentam um padrão geomorfológico e geológico semelhante, resultando em incremento de informações geradas previamente em áreas de referência.

O objetivo da Pedometria é, portanto, conseguir uma melhor compreensão do solo como um elemento do meio físico que varia ao longo de diferentes escalas no espaço e no tempo, contribuindo, portanto, na melhoria nas técnicas de manejo e para o conhecimento científico do solo, em termos agronômicos, ecológicos, ambientais, culturais e ainda hidrológicos (DALMOLIN; TEN CATEN, 2015). As técnicas do MDS, da mesma forma que as tradicionais, consistem no estabelecimento de relações do solo com a paisagem, porém, por meio de técnicas mais quantitativas em relação aos mapeamentos tradicionais. Para isso, utilizam-se modelos numéricos ou estatísticos para inferir as variações espaciais dos solos na paisagem, a partir de mapas já existentes, de observações (ou coletas) em campo ou de variáveis ambientais correlacionadas (TESKE, et al., 2015).

Segundo Coelho e Giasson (2010), esses mapeamentos se baseiam na criação de informações que possibilitem estabelecer relações matemáticas entre variáveis ambientais (atributos topográficos) e classes de solos e, assim, predizer a distribuição espacial dessas classes com significativa semelhança aos mapas gerados por meios convencionais. Com os MDS, é possível constituir diversas relações entre atributos topográficos (AT) provenientes de um modelo digital do terreno com os compartimentos pedológicos de forma a aplicá-las no mapeamento de solos.

Uma técnica estatística aplicada, mesmo que ainda de forma incipiente, no mapeamento pedológico preditivo é o da regressão logística múltipla multinomial. Ela tem como objetivo produzir, a partir de um conjunto de observações, um modelo que permite a predição de valores tomados por uma variável categórica, utilizando uma série de variáveis explicativas (MOURÃO-JUNIOR, 2007; TEN CATEN et al., 2011). Esse método foi avaliado e contribuiu com resultados satisfatórios na espacialização das classes de solos em trabalhos como Bailey et al. (2003), Hengl et al. (2007), Figueiredo et al. (2008), Giasson et al. (2008), Debella-Gilo e Etzelmuller (2009), Kempen et al. (2009), Ten Caten et al. (2011) e Souza (2013), Souza et al. (2016) e Nascimento et al. (2017).

Conforme destaca Ten Caten et al. (2011), no Brasil o número de trabalhos publicados é considerado pequeno e existe ainda uma grande lacuna no conhecimento para a aplicação dessas técnicas de modelagem linear generalizada. Dentre as principais contribuições, pode-se citar os trabalhos em escala semidetalhada realizados por Giasson et al. (2006; 2008) e Figueiredo et al. (2008). Por ser utilizada mais que uma variável explicativa, o modelo é considerado múltiplo e, pelo fato de poder predizer mais que duas classes, é chamado de multinomial (ou politômico); logo, o mesmo é denominado de regressão logística múltipla multinomial, que é entendido como uma generalização do modelo logístico simples (COELHO; GIASSON, 2010; TEN CATEN, 2011b).

Segundo Ten Caten et al. (2011) os MDS são aplicados na perspectiva de predizer ou extrapolar as informações a respeito da distribuição espacial dos solos. As regressões logísticas múltiplas têm potencialidade de serem aplicadas em situações quando o resultado da inferência pode ocorrer sob muitas categorias. Essas regressões permitem avaliar a probabilidade de ocorrência de uma determinada variável, considerando os valores das diversas variáveis independentes que podem ser qualitativas ou quantitativas, categóricas ou contínuas (HENGL et al., 2007; COELHO, 2010; LIMA et al., 2013).

Nesse mesmo sentido, as regressões logísticas não têm qualquer exigência para sua aplicação no que diz respeito à organização das variáveis explicativas, não havendo necessidade de possuir distribuição normal, 
correlação linear, medidas em mesma escala ou homogeneidade de variância. As variáveis explicativas podem ser, ainda, uma combinação de dados contínuos, discretos ou binários, como os atributos topográficos (CHATTERJEE; HADI, 2006; TEN CATEN et al., 2011).

Da mesma forma como no levantamento pedológico convencional, o MDS também faz uso de informações coletadas em campo ou disponíveis em pontos de observação de solos oriundos de mapeamentos pedológicos preexistentes. Essas informações são utilizadas para ajustar o modelo quantitativo pois contém variáveis relativas às condições da distribuição dos solos do local. Por fim, o modelo ajustado é empregado para predizer propriedades do solo ou classes de solos para o restante da área (LAGACHERIE, 2008).

Lagacherie (2008) adverte ainda que um conjunto de dados cartográficos e topográficos de qualidade é um fator chave para efetivar um MDS com precisão e avaliar a qualidade dos seus resultados, sendo que a disponibilidade desses dados é um fator limitante que pode diminuir os avanços dos mapeamentos digitais de solos. É pertinente salientar que pelo fato dos MDS se basearem na relação dos solos com o relevo (McBRATNEY et al., 2013), a aplicação desse método de mapeamento tem eficiência comprovada em locais que apresentam contrastes nítidos de relevo, como por exemplo na Serra do Mar, cuja transição das planícies para os morros e serras é nitidamente marcada (SILVEIRA et al., 2013; NOWATZKI; SANTOS, 2014), portanto, o desafio imposto é aplicar esse método em relevos suaves.

No Brasil, as classes dos Latossolos e dos Argissolos representam mais de 50\% do território nacional (SANTOS et al., 2018). A presença destes solos está frequentemente associada a relevos suavemente ondulados, com os Latossolos predominando no terço superior e os Argissolos no terço médio das vertentes, constituindo em sistemas de transformação lateral, já estudado por diversos autores na região noroeste do Paraná (CUNHA et al., 1999; NAKASHIMA, 1999; CUNHA et al., 2008; SILVA et al., 2011; BECKAUSER; SILVEIRA; 2020). A associação desses solos com relevos pouco contrastados dificulta o mapeamento pedológico tradicional, principalmente pela falta de parâmetros de relevo que possam servir de base para definir o limite que separa uma classe de solos da outra.

Assim sendo, a partir da aplicação o método das regressões logísticas para um MDS na escala 1:100.000 e nas características do solo-relevo da região, procurou-se definir parâmetros morfológicos que possam auxiliar na delimitação dos Latossolos para os Argissolos ao longo das vertentes. Para tanto, foi selecionada a área de estudo que corresponde ao baixo curso da bacia hidrográfica do rio Ivaí (Figura 1), com extensão de aproximadamente $9.600 \mathrm{~km}^{2}$, na região noroeste do estado do Paraná.

\section{2. Área de Estudo}

A bacia do rio Ivaí é a segunda maior do estado do Paraná e apresenta uso e cobertura das terras diversificado, porém eminentemente agrícola - com o plantio extensivo de soja, milho e cana de açúcar - e pecuária. Segundo Santos et al. (2013), a rápida ocupação desta bacia, a partir da década de 1940, promoveu intenso desmatamento da vegetação original, as substituindo por campos agropecuários, de tal maneira que atualmente restam menos de $9 \%$ de sua cobertura florestal original, o que alterou eminentemente o comportamento do escoamento hídrico de superfície e subsuperfície.

A caracterização geológica é composta principalmente pelo Grupo Caiuá que é um conjunto de rochas sedimentares (arenitos) depositadas em um ambiente desértico no período Cretáceo (Mesozóico) e que recobre $84 \%$ da área de estudo. Neste grupo, a formação geológica que ocupa a maior extensão da área de estudo é a Formação Rio Paraná, seguida pelas formações Goio Erê (depósitos eólicos periféricos) e Santo Anastácio (planície de lençóis de areia) (FERNANDES; COIMBRA, 1994; MINEROPAR, 2001; FERNANDES et al., 2012; BECKAUSER; SILVEIRA; 2020). Ainda é encontrado na área de estudo o Grupo São Bento, representado pela Formação Serra Geral, sendo constituída por extensos derrames de rochas ígneas, predominando basaltos, de idade jurássicacretácea (MINEROPAR, 2001) e por Sedimentos Cenozoicos inconsolidados oriundos da erosão de materiais de litologias mais antigas intemperizadas localizadas na planície fluvial do rio Ivaí (MINEROPAR, 2001).

Inserido no Terceiro Planalto Paranaense (MAACK, 1981), a área de estudo possui duas divisões morfológicas: planícies (fluviais) e planaltos (de Campo Mourão, Paranavaí e Umuarama) de acordo com SANTOS et al. (2006). Nakashima (1999) caracterizou a região com predomínio de relevos uniformes e suaves, com planaltos escalonados, inclinados levemente em direção ao vale do rio Paraná.

Para Nakashima (op. cit), os solos são predominantemente espessos, em geral com textura variando de arenosa a média/argilosa, o que lhe confere elevada suscetibilidade ao desenvolvimento de processos erosivos. As 
porções na vertente onde há a transição de Latossolos para Argissolos apresentam maior probabilidade de ocorrência da intensificação desses processos erosivos. Por essa razão, a confecção de mapas pedológicos com maior detalhamento é de extrema importância para auxiliar nas técnicas de manejo e conservação dos solos dessa região do estado.

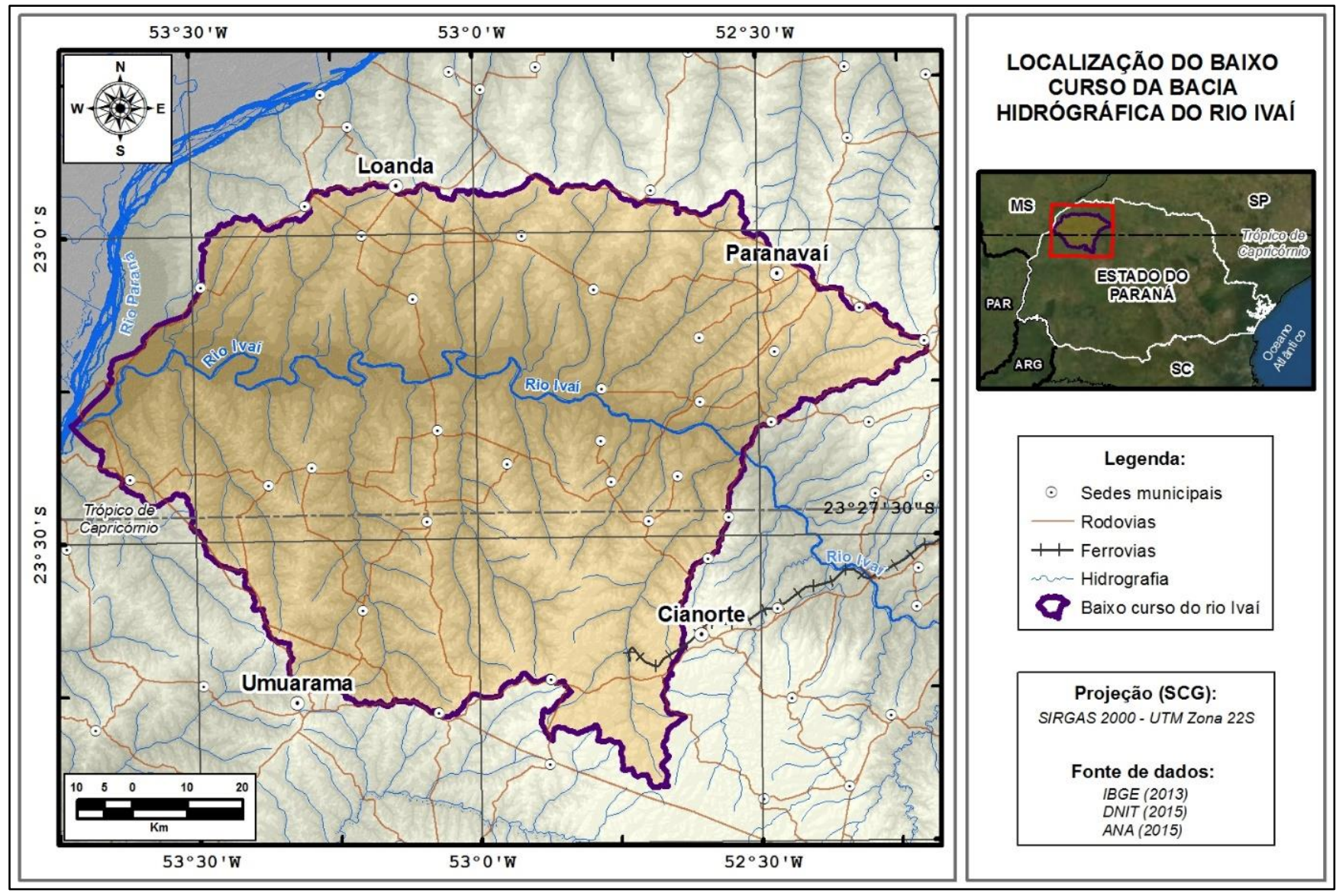

Figura 1. Localização do baixo curso da bacia hidrográfica do rio Ivaí

$\mathrm{Na}$ área de estudo, encontram-se ainda extensas planícies fluviais, associadas aos rios Ivaí e Paraná (mais à jusante). Essas planícies referem-se às porções dos vales fluviais constituídas de sedimentos aluviais que circundam o curso de água e são periodicamente inundadas pela dinâmica da rede de drenagem, permanecendo o nível freático próximo da superfície grande parte do ano (IBGE, 2009; CHRISTOFOLETTI, 2011). Nesses ambientes podem ser encontrados Gleissolos, Organossolos e ainda Neossolos Flúvicos (NAKASHIMA, 1999).

\section{Materiais e Métodos}

\subsection{Base de dados}

A base de dados planialtimétricos utilizada foi disponibilizada pelo Instituto de Terras Cartografia e Geociências (ITCG) na escala 1:50.000 e a hidrografia, pelo Instituto das Águas do Paraná. A partir da base de dados, o Modelo Digital do Terreno (MDT) foi gerado por meio do software ArcGISTM 10.3, desenvolvido pela ESRI (Environmental Systems Research Institute), com a ferramenta Topo to Raster disponível no módulo Spatial Analyst Tools. Essa ferramenta se baseia no método de interpolação denominado Topogrid proposto por Hutchinson (1989). Esse método foi projetado a partir do programa ANUDEM (Australian National University Digital Elevation Model), baseado em um algoritmo determinístico (drenagem forçada) que possibilita criar um modelo que simule um livre deflúvio (escoamento) superficial, estabelecendo, portanto, modelos topográficos hidrologicamente consistentes (SILVA; OKA-FIORI; SILVEIRA 2017). 
$\mathrm{Na}$ área de estudo ocorre uma extensa planície fluvial (referente aos rios Ivaí e Paraná) e conforme publicado em Nowatzki et al. (2018), essa planície foi delimitada por meio dos atributos índice de posição topográfica e do índice topográfico de umidade modificado. Esses dados foram utilizados para compor a classe de planície fluvial da área de estudo.

\subsection{Atributos topográficos}

Para a elaboração dos atributos topográficos (AT), foram utilizados os softwares ArcGIS ${ }^{\text {TM }} 10.3$ e o SAGA GIS ${ }^{\mathrm{TM}}$ 5.0.0 (System for Automated Geoscientific Analyses). Os atributos selecionados foram:

\subsubsection{Clinografia (CLN) (slope)}

Este índice foi elaborado a partir da análise das distâncias entre curvas de nível e representa, de forma contínua, a inclinação e as formas do relevo (DE BIASI, 1992; MOORE, et al., 1993; NOWATZKI; SANTOS, 2014; SANTOS, 2015).

\subsection{2. Índice de Posição Topográfica (IPT)}

Índice proposto por Weiss (2001), derivado de um algoritmo que mede a diferença entre a elevação do ponto central e a média da elevação ao seu redor (vizinhança) com um raio predeterminado. A análise de vizinhança foi efetuada por uma janela circular (empregada neste trabalho com o valor de $\mathrm{R}=50$ pixels). Esse procedimento metodológico foi realizado a partir da ferramenta Focal Statistics, presente também no módulo Spatial Analyst tools do software ArcGIS 10.3.

\subsection{3. Índice de rugosidade do terreno (IRG)}

O índice de rugosidade em ambiente digital, foi elaborado pela primeira vez por Hobson (1972, apud SAMPAIO; AUGUSTIN, 2014), baseia-se no uso da variação da declividade para representar as formas de relevo. Esse índice é obtido a partir da razão entre área superficial (irregularidade da superfície) e a área planar (superfície reduzida ao plano), sendo as informações obtidas por meio de técnicas de levantamento em campo, ou a partir de dados no formato digital (RILEY; DeGLORIA.; ELLIOT, 1999; SAMPAIO, 2008; SAMPAIO; AUGUSTIN, 2014; FUMIYA et al., 2016; RÓŻYCKA; MIGOŃ; MICHNIEWICZ, 2016). Esse índice foi gerado no software SAGA 5.0.0 por meio da ferramenta Terrain Roughness Index (índice de rugosidade do terreno, ou IRG) que calcula a diferença média da elevação entre o pixel central e os oito pixels circundantes, ou seja, a partir da elevação do pixel central, pela qual o valor do IRG é calculado, subtraem-se os valores da vizinhança. As diferenças resultantes são multiplicadas por elas mesmos, somadas e elevadas ao quadrado novamente. Semelhante ao empregado para calcular o IPT, foi usada a ferramenta Focal Statistics para uma melhor representação dos solos a serem preditos (usando um raio de 15 pixels para os três modelos usados neste trabalho).

\subsection{4. Índice topográfico de umidade (ITU)}

Este índice é usado para caracterizar a distribuição espacial de zonas de saturação superficial e conteúdo de água nas paisagens (MOORE et al., 1993; WILSON; GALLANT, 2000; NOWATZKI; SANTOS, 2014; HUNG; SIEFERT; SANTOS, 2017). Para Moore et al. (1993), esse índice tem a potencialidade de demonstrar os efeitos do relevo na localização e extensão das áreas de acumulação de água. Sirtoli (2008) destaca que esse índice é definido como uma função da declividade e da área de contribuição por unidade de largura ortogonal à direção do fluxo. Entretanto, Böhner e Selige (2006) propuseram uma modificação na área de contribuição inserindo, portanto, um limite superior para as áreas de contribuição, ou seja, para cada valor de declividade é estipulada uma área de contribuição máxima. Desse modo, valores acima desses limites são homogeneizados, principalmente em áreas aplainadas de fundo de vale, cujo objetivo é minimizar a existência de valores aleatórios e fora do padrão em áreas mais planas (HUNG; SIEFERT; SANTOS, 2017).

Assim, optou-se por usar a ferramenta SAGA Wetness Index presente dentro do software SAGA 5.0.0, que representa o índice topográfico de umidade modificado (ITM).

\subsubsection{Plano de Curvatura (PLA)}


É empregado para identificar áreas de diferentes regimes de umidade, permitindo uma avaliação mais acurada da distribuição dos solos na paisagem pois separa áreas divergentes/convergentes dos fluxos de matéria sobre o terreno quando analisado em projeção horizontal (VALERIANO; CARVALHO JÚNIOR, 2003; SILVEIRA, 2010).

\subsection{Predição das classes de solos}

Como método para a predição de solos, através de uma relação linearizada entre covariáveis preditoras e classes de solos, as regressões logísticas estabelecem um valor de pertinência (probabilidade de ocorrência) para cada classe a ser mapeada (VENABLES, W. N.; RIPLEY, 2002; GIASSON et al., 2006). Esse valor de probabilidade é posteriormente avaliado entre todas as classes para um mesmo ponto, sendo que entre elas, a classe de maior valor é atribuída à coordenada em análise, gerando-se, consequentemente, um mapa de classe de solos. Para Ten Caten (2011) sua aplicação envolve a função logarítmica (ou logit), a qual é definida como a razão entre a probabilidade de o evento ocorrer e a probabilidade de ele não ocorrer (odds ou razão de chance); ou, ainda, a logit é a função logarítmica da razão entre a probabilidade (pi) de um pixel ser pertencente a uma classe de solo "i" e a probabilidade de não ser (1 - pi). Seu valor pode ser determinado por meio da regressão:

$$
\operatorname{logit}_{i}=\ln \left(\frac{p_{i}}{1-p_{i}}\right)=a+b_{0}+b_{1} X_{1}+b_{2} X_{2}+\ldots+b_{k} X_{k}
$$

A equação demonstra como calcular o logit de uma categoria predita a partir de um conjunto de variáveis (Xi...k). O logit é, por conseguinte, o logaritmo natural de uma razão entre probabilidades. O valor de "a" indica o intercepto da regressão e os valores de " $b$ " são os coeficientes de cada variável explicativa (CHATTERJEE; HADI, 2006; TEM CATEN et al., 2011), ou seja, todos os valores de "a" e " $b$ " das regressões foram determinadas para cada classe de solo a partir de dados experimentais (DEBELLA-GILO e ETZELMULLER, 2009).

Fundamentado nas contribuições de Nascimento et al. (2017) para a concretização das regressões logísticas, foi utilizada uma interface dentro do software QGIS ${ }^{\mathrm{TM}}$ versão 2.14.22 com o software $\mathrm{R}^{\mathrm{TM}}$, que é uma linguagem e um ambiente de desenvolvimento integrado para cálculos estatísticos e elaboração de gráficos. Dentro do R, usase para a regressão logística a função multinom do pacote nnet. Pela interface do QGIS acessa-se o módulo modelling e em seguida a ferramenta Spatial environmental modelling. Por fim, dentro do item Learner seleciona-se o aprendiz estatístico Penalized Multinomial Regression. Esse aprendiz usa o termo "penalizada" pois é necessário atribuir pesos de confiança nas amostras inseridas na regressão. Conforme Nascimento et al. (2017), deve-se, teoricamente, introduzir valores entre 0.00 e 1.00, sendo zero (0) para indicar nenhuma confiança na informação colocada e um (1) a absoluta certeza da classe de solo daquele ponto (no caso de coletas de dados pedológicos de campo). Na prática, esses autores sugerem que sejam atribuídos valores entre 0.50 e 0.80 na qual eles intitulam de pseudoamostras, que são amostras simuladas.

Os critérios para a escolha e delimitação das áreas de referência foram os seguintes: i) locais onde a passagem lateral dos Latossolos para Argissolos pudesse ser melhor representada para o contexto geral da área de estudo; ii) diferentes comportamentos geomorfométricos (atributos topográficos analisados em segundo plano no software); iii) bacias de no máximo terceira ordem conforme Strahler (1952); iv) valor de área dessas bacias entre no mínimo $10 \mathrm{~km}^{2}$ e no máximo $30 \mathrm{~km}^{2}$. Portanto, foram definidas como as duas Unidades de Mapeamento (UM): Latossolos como UM-01 e Argissolos como UM-02. As áreas de referência (Figura 2) foram definidas a partir da delimitação de 16 sub-bacias hidrográficas no interior dos municípios contemplados pelo mapeamento pedológico preexistente de Fasolo et al. (1988) (Paranavaí, Loanda, Santa Izabel do Ivaí, Santa Mônica, Guaporema e Rondon) na escala 1:55.000 (mapeamento semidetalhado). Toda a base encontrava-se em formato analógico e foi convertida (vetorizada) em ambiente SIG para formato digital, georreferenciada e transformada em arquivo vetorial utilizando o software Arcgis 10.3. Esses dados foram ainda atualizados para a atual classificação de solos conforme está descrito no Sistema Brasileiro de Classificação de Solos, ou SiBCS (SANTOS et al., 2018). 


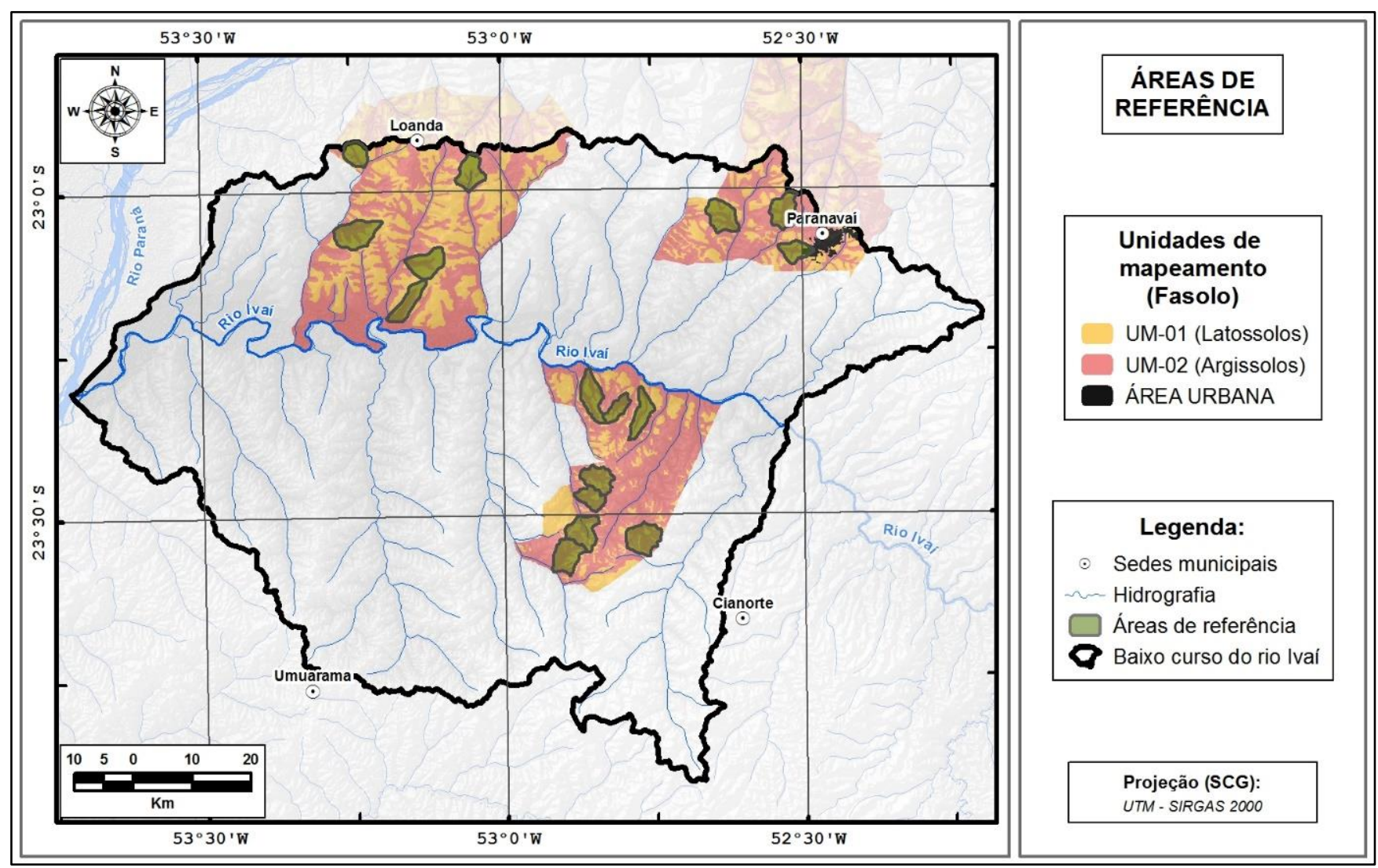

Figura 2. Áreas de referência (sub-bacias hidrográficas) e unidades de mapeamento de Fasolo et al. (1988)

A partir do mapeamento preexistente foi possível estabelecer pontos de controle (pseudoamostras) para aplicação do método das regressões logísticas (NASCIMENTO et al., 2017). O número total de pseudoamostras adotado neste estudo foi de 1.200, sendo que o número mínimo de amostras para cada uma das áreas de referência foi de 60 (totalizando 960). Os 240 pontos restantes foram efetivados de três maneiras: a primeira na distribuição de pontos ao longo das áreas de referência a partir das informações do mapeamento de Fasolo et al. (1988); a segunda na análise de proximidade de curvas de nível juntamente com uma camada de clinografia habilitada no ArcGis. Deste modo foi possível determinar locais com rupturas de declives, mesmo que suaves, que marcassem a potencial transição entre os principais solos das duas unidades de mapeamento em questão. Priorizou-se ainda áreas onde os valores do atributo fossem muito altos ou muito baixos, de modo que as regressões logísticas fossem induzidas a estabelecer a unidade de mapeamento correta no mapeamento preditivo.

A terceira maneira foi a partir da análise de imagens de satélites disponibilizadas pelo mesmo software (Basemap/Imagery, GeoEye01 - Resolução: 0,46m - Data: 14/08/2016). Buscou-se por áreas com solo exposto que evidenciasse mudanças na cor ao longo das vertentes. Para Cunha, Castro e Salomão (1999), na região noroeste do Paraná a cor do solo varia ao longo das vertentes, podendo inferir mudança de classe de solos. Levou-se em consideração também a presença de feições erosivas em ambientes rurais. Segundo Nakashima (1999), Cunha, Castro e Salomão (1999) e Santos e Castro (2006) essas feições podem apresentar indicativos de erosão hídrica superficial e subsuperficial que ocorrem quando há formação de horizonte Bt no solo.

Com base nos critérios propostos por Nascimento et al. (2017), os pesos de confiança usados para a inserção das pseudoamostras foram 0.60 para pontos próximos dos limites das classes de solos do mapeamento de Fasolo et al. (1988) e 0.80 para o restante dos pontos (distante de limites). A escolha desses valores foi baseada nas imprecisões ocorridas no georreferenciamento dos mapas de solos, por isso a confiança maior ocorre nos pontos localizados no centro dos polígonos e os pontos com menor confiança próximo dos limites das classes de solos do mapa. No total, foram estabelecidos 432 pontos para a classe Latossolos e 768 para a classe Argissolos. Essa classe recebeu maior número de pontos por representar porções do relevo com maior heterogeneidade de informações. 


\subsection{Verificação de qualidade}

A validação do modelo preditivo foi feita com a inserção dos pontos de controle (amostras) extraídas tanto de trabalhos preexistentes quanto de observações de campo. Ou seja, foi validado quantos pontos denominados de Latossolos se localizam dentro da classe espacializada por Latossolos (acertos) e quantos desses se localizaram na de Argissolos (erros). Destaca-se que essa validação também foi gerada automaticamente por meio da estatística das pseudoamostras (chamado pelo software de validação cruzada). Nas duas validações foram utilizadas a Acurácia Geral e o Índice Kappa como técnicas de verificação de qualidade. As amostras de controle foram obtidas por meio de sondagens em topossequências com intervalos regulares (uma no topo, uma na média vertente e outra na baixa vertente) com trado manual (trado holandês) para identificar determinadas características morfológicas do solo (BOULET et al., 1982; FERNANDES BARROS, 1985).

Seguindo as determinações do manual de descrição e coleta de solos no campo IBGE (2015) e Santos et al. (2018) foram analisadas as características morfológicas de cor, textura, transição, profundidade e espessura dos horizontes. Ainda foram extraídos pontos de controle de trabalhos preexistentes da região da área de estudo, Larach et al. (1984), Cunha, Nobrega e Castro (2008), Silva, Fidalski e Bertol (2011) e IBGE (2018). A somatória dos pontos de controle, tanto por observações de campo quanto de trabalhos preexistentes, totalizou 43 pontos. Para a verificação de qualidade da predição, foi utilizado como referência o mapa de solos de Fasolo et al. (1988). Para esse procedimento de verificação foi utilizado os métodos de acurácia geral (AG), matriz de erros e acurácia do mapeador (AM) e do usuário (AU), índice kappa (K) e validação cruzada (VC). Cabe destacar que a legenda desse mapeamento contém a descrição original com a nomenclatura do sistema de classificação da época. Cada classe de solo foi convertida para o atual SiBCS (SANTOS et al., 2018) e posteriormente feito um enquadramento conforme as unidades de mapeamento selecionadas neste trabalho (unidades de Latossolos e Argissolos).

Por fim, foram efetuadas generalizações cartográficas (remoção de ruídos) dos resultados com o intuito de atender a área mínima mapeável. A equivalência desta área no mapa, com a correspondente no terreno, é função da escala final de apresentação. Portanto, para a escala adotada de 1:100.000, escala de nível de reconhecimento de alta intensidade, a área mínima mapeável é de $0,4 \mathrm{~km}^{2}\left(400.000 \mathrm{~m}^{2}\right)$, conforme IBGE (2015).

\section{Resultados e discussão}

\subsection{Mapa digital de solos}

Por meio das 1.200 pseudoamostras inseridas nas dezesseis áreas de referência e com a escolha dos cinco atributos topográficos que pudessem contribuir na espacialização dos solos da região, foi possível realizar o mapeamento preditivo proposto por regressão logística com resolução espacial de 20 metros conforme a Figura 3. A unidade de mapeamento 01 representam os Latossolos enquanto a unidade 02, os Argissolos ao longo do baixo curso do rio Ivaí. Na totalização dos dados houve maior distribuição da classe de Argissolos, com 54\%. No setor sul da bacia houve distribuição ainda maior desta classe (60\%) em função do relevo ser mais ondulado quando comparado ao setor norte (Tabela 1)

Tabela 1. Quantificação das áreas das unidades de mapeamento

\begin{tabular}{cccc}
\hline Unidade de Mapeamento & Pixels & $\mathbf{k m}^{\mathbf{2}}$ & $\mathbf{\%}$ \\
\hline \multicolumn{5}{c}{ NORTE } \\
\hline UM-01 & 4.791 .746 & $1.916,70$ & 53,70 \\
\hline UM-02 & 4.131 .224 & $1.652,49$ & 46,30 \\
$\Sigma$ & 8.922 .970 & $3.569,19$ & 100,00 \\
\hline \multicolumn{5}{c}{} \\
\hline UM-01 & 4.887 .716 & $1.955,09$ & 39,26 \\
UM-02 & 7.561 .198 & $3.024,48$ & 60,74 \\
$\Sigma$ & 12.448 .914 & $4.979,57$ & 100,00 \\
\hline \multicolumn{5}{c}{ TOTAL } \\
\hline UM-01 & 9.679 .462 & $3.871,78$ & 45,29 \\
UM-02 & 11.692 .422 & $4.676,97$ & 54,71
\end{tabular}




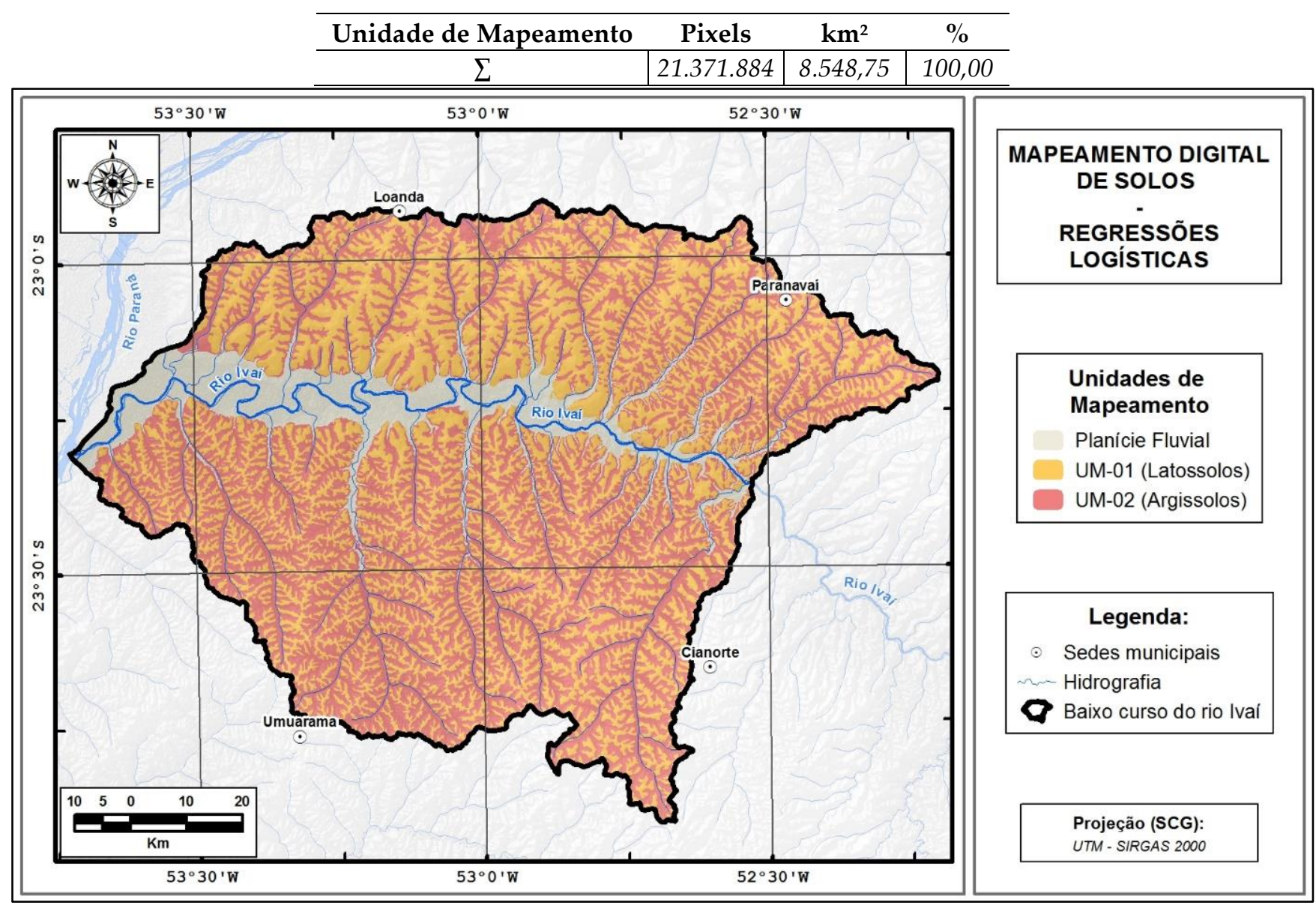

Figura 3. Predição das unidades de mapeamento por Regressões Logísticas: UM-01 representando a distribuição dos Latossolos, e a UM-02 dos Argissolos

A avaliação dos 1.200 pontos de controle (pseudoamostras) foi realizada por meio da análise de estatística descritiva de cada um dos cinco atributos topográficos, sendo utilizados os parâmetros de média (aritmética), mediana, moda, desvio padrão, variância, intervalo (amplitude dos dados), valores mínimos e máximos (Tabela 2). Os dados também foram apresentados em forma de boxplot (variação dos dados de pseudoamostras) ilustrados conjuntamente na Figura 4.

Tabela 2. Pontos de controle - variação dos dados

\begin{tabular}{c|ccc|cc|ccc}
\hline UM & Média & Mediana & Moda & $\begin{array}{l}\text { Desvio } \\
\text { padrão }\end{array}$ & Variância & Intervalo & Mín. & Máx. \\
\hline \multicolumn{7}{c}{ Clinografia } \\
\hline UM-01 & 4,168 & 4,007 & 11,776 & 2,607 & 6,798 & 16,051 & 0,041 & 16,092 \\
UM-02 & 8,163 & 7,048 & 15,453 & 6,155 & 37,883 & 46,493 & 0,45 & 46,943 \\
\hline \multicolumn{7}{c}{ Índice e Posição Topográfica } \\
\hline UM-01 & 9,7 & 9,165 & $-6,66$ & 8,541 & 72,949 & 62,056 & $-23,279$ & 38,777 \\
UM-02 & $-11,499$ & $-10,551$ & $-12,559$ & 11,887 & 141,293 & 76,174 & $-42,772$ & 33,402 \\
\hline \multicolumn{7}{c}{ Índice de Rugosidade do Terreno } \\
\hline UM-01 & 6,88 & 6,693 & 14,023 & 3,266 & 10,666 & 17,169 & 0,398 & 17,567 \\
UM-02 & 11,103 & 10,933 & 12,85 & 3,849 & 14,814 & 28,817 & 1,248 & 30,065 \\
\hline \multicolumn{7}{c}{ Índice Topográfico de Umidade modificado } \\
\hline
\end{tabular}




\begin{tabular}{c|ccc|cc|ccc}
\hline UM & Média & Mediana & Moda & $\begin{array}{c}\text { Desvio } \\
\text { padrão }\end{array}$ & Variância & Intervalo & Mín. & Máx. \\
\hline UM-01 & 7,756 & 7,464 & 6,175 & 1,578 & 2,489 & 8,632 & 4,568 & 13,201 \\
UM-02 & 9,777 & 9,852 & 7,672 & 2,899 & 8,405 & 13,925 & 3,33 & 17,254 \\
\hline \multicolumn{7}{c}{ Plano de Curvatura } \\
\hline UM-01 & 0,007 & 0,006 & 0,008 & 0,007 & 0 & 0,044 & $-0,012$ & 0,032 \\
UM-02 & $-0,002$ & $-0,003$ & 0,005 & 0,011 & 0 & 0,146 & $-0,058$ & 0,088 \\
\hline
\end{tabular}

Os valores dos pontos de controle apresentaram no atributo clinografia médias aritméticas menores para a UM-01 em relação a UM-02. Salienta-se que mesmo considerando que porções das vertentes com baixa clinografia (abaixo de 8 graus) se enquadrem na classe UM-01 e a tendência que a maioria dos pontos fique com os valores deste índice próximos (em torno de 4 graus), a quantidade de pseudoamostras para este grupo foi menor (432 dos 1.200 pontos). Priorizou-se que a maioria dos pontos fossem inseridos na classe UM-02 pois essa ocorre em contextos geomorfológicos mais diversificados (terços médios e inferiores de vertente ou até mesmo em vales) que na classe UM-01. Isso é corroborado pelo desvio padrão e a variância apresentaram valores maiores para a classe UM-02 que se repete nos demais atributos topográficos.

Deve-se destacar que alguns dos pontos inseridos fora das áreas de referência compõem os outliers no boxplot, e se enquadram nas feições de relevo anômalos, ou seja, não estão entre o primeiro e terceiro quartil (50\% dos dados ilustrados no boxplot), distantes também da média, mediana e moda. Elas correspondem as feições erosivas estabilizadas, apresentando de um modo geral valores de clinografia bastante altos, assim como no índice de rugosidade do terreno e plano de curvatura.

Os resultados do IPT mostram que na classe UM-01 os valores interquartis são maiores que zero e representam os terços superiores das vertentes, enquanto os valores inferiores a zero e com maior dispersão se enquadraram na classe UM-02, localizados majoritariamente nos terços inferiores das vertentes. O IRG apresentou valores de UM02 mais altos, tendo em vista que este índice detecta as porções do relevo onde o relevo é mais acidentado. O ITM foi o atributo com valores mais próximos entre as duas unidades, podendo ser notado na média, mediana e moda, devido as características topográficas da área de estudo. Em contrapartida, no plano de curvatura houve concentração dos valores para ambas as classes refletindo, portanto, que houve boa representação das duas classes mapeadas.

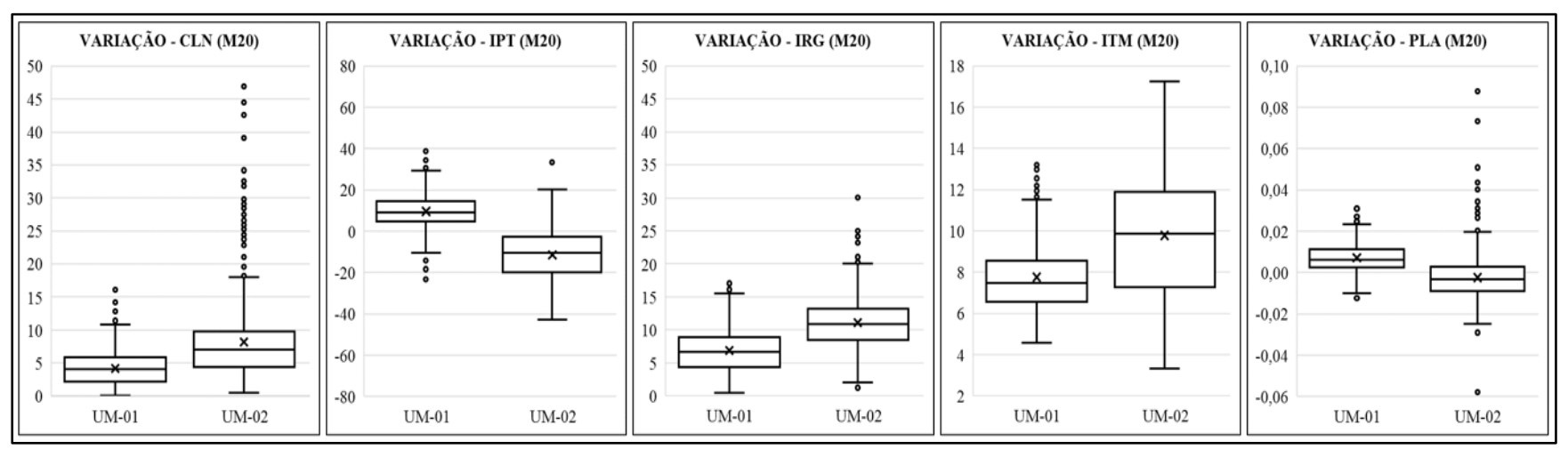

Figura 4. Boxplots de pseudoamostras nos atributos topográficos

\subsection{Validação do modelo}

Para a conferência da qualidade do modelo predito, foi usado o mapeamento pedológico de Fasolo et al. (1988) tendo como parâmetros de análise de qualidade a matriz de erro, concordância, discordância, acurácia geral, acurácia do mapeador e do usuário e o índice Kappa (Figura 5). 


\begin{tabular}{|c|c|c|c|c|c|}
\hline \multirow{2}{*}{\multicolumn{2}{|c|}{ CLASSES }} & \multicolumn{4}{|c|}{ PREDIÇÃO: RL - MDT 20} \\
\hline & & UM-01 & UM-02 & $\sum$ linha & AM \\
\hline \multirow{4}{*}{ 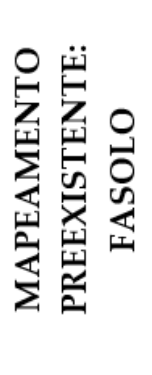 } & UM-01 & 1.513 .836 & 389.139 & 1.902 .975 & $79,55 \%$ \\
\hline & UM-02 & 809.461 & 1.927 .596 & 2.737 .057 & $70,43 \%$ \\
\hline & $\sum$ coluna & 2.323.297 & 2.316 .735 & $\begin{array}{l}\sum \text { total }= \\
4.640 .032\end{array}$ & Карра $=0,48$ \\
\hline & AU & $65,16 \%$ & $83,20 \%$ & $\mathrm{AG}=0,74$ & $\begin{array}{l}C \%=74,17 \\
D \%=25,83\end{array}$ \\
\hline
\end{tabular}

Figura 5. Matriz de erros: predição por regressões logísticas com mapeamento preexistente

O método das regressões logísticas permitiu a geração de um modelo preditivo acurado e apresentou resultados satisfatórios em relação aos índices de qualidade que foram proporcionais a sua resolução espacial. $\mathrm{O}$ modelo apontou acurácia geral de 0,74 , ou seja, $74 \%$ de acerto em relação ao mapeamento preexistente. Ainda foi obtido o valor de 0,48 para o índice Kappa. Pela verificação da qualidade do mapeamento, foi possível também fazer a relação de quantos pontos de controle, tanto pseudoamostras quanto amostras, acertaram a sua informação em relação ao mapa preditivo final. Foi possível verificar a quantidade de acertos das 1.200 pseudoamostras (validação cruzada) e das 43 amostras (validação), de acurácia geral e índice Kappa realizados a partir das regressões logísticas (Tabela 3).

Tabela 3. Verificação da qualidade por validação cruzada e validação

\begin{tabular}{|c|c|c|c|c|c|c|c|}
\hline Técnica & Qualidade & & etor norte & & Setor sul & & $\mathrm{AE}$ \\
\hline \multirow{3}{*}{$\begin{array}{c}\text { Validação } \\
\text { cruzada }\end{array}$} & Pseudoamostras & 600 & \multirow{3}{*}{$\begin{array}{c}\text { Acertos }=532 \\
\text { Erros }=68\end{array}$} & 600 & \multirow{3}{*}{$\begin{array}{c}\text { Acertos }=547 \\
\text { Erros }=53\end{array}$} & 1200 & \multirow{3}{*}{$\begin{array}{c}\text { Acertos }=1079 \\
\text { Erros }=121\end{array}$} \\
\hline & AG & 0,89 & & 0,91 & & 0,90 & \\
\hline & Kappa & 0,77 & & 0,80 & & 0,78 & \\
\hline \multirow{3}{*}{ Validação } & Amostras & 17 & \multirow{3}{*}{$\begin{array}{c}\text { Acertos }=15 \\
\text { Erros }=2\end{array}$} & 26 & \multirow{3}{*}{$\begin{array}{c}\text { Acertos }=22 \\
\text { Erros }=4\end{array}$} & 43 & \multirow{3}{*}{$\begin{array}{c}\text { Acertos }=37 \\
\text { Erros }=6\end{array}$} \\
\hline & AG & 0,88 & & 0,85 & & 0,86 & \\
\hline & Kappa & 0,75 & & 0,70 & & 0,72 & \\
\hline
\end{tabular}

Os valores de verificação por AG ficaram acima de 0,85 (85\% de acerto) e os valores gerados para o índice Kappa podem ser considerados bastante satisfatórios por se encontrarem entre valores de 0,7 a 0,8. Ten Caten (2008) afirma que de acordo com testes de modelos preditivos aplicados ao mapeamento de solos, valores na ordem entre 0,30 a 0,60 são considerados de boa qualidade. A Figura 6 permite avaliar quais as porções das vertentes tiveram acertos e erros em relação as duas unidades de mapeamento ao serem comparadas com o mapeamento de Fasolo et al. (1988). Foram representadas quatro áreas de referência, sendo duas no setor norte (AR_N01 e AR_N08) e duas no setor sul (AR_S04 e AR_S08). 

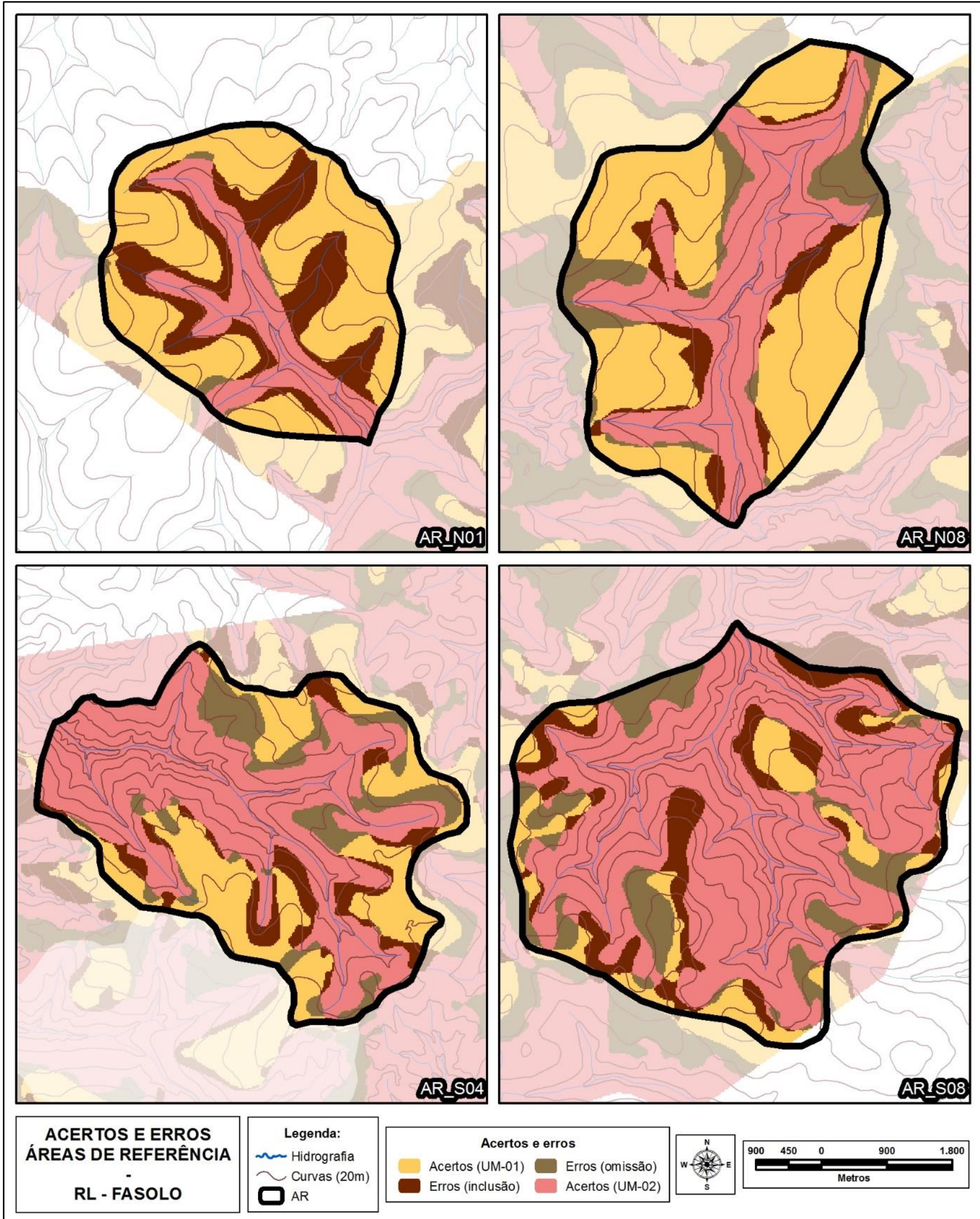

Figura 6. Acertos e erros do mapeamento digital de solos em áreas de referência

A partir da análise da área de referência 01 (AR_N01) fica evidente o ganho de informação que a predição proporciona, levando em consideração as características geomorfológicas semelhantes de sua área ao se observar as curvas de nível. Porém, nessa área de referência, apenas ocorrem acertos nos terços inferiores da porção oeste 
da mesma, apresentando na porção leste, polígonos referentes aos erros de inclusão. Ainda pode-se verificar que o setor norte possui menos áreas com erros de omissão em comparação com o setor sul, evidenciando que pode haver uma supervalorização da classe UM-02 neste setor, pois é possível notar que alguns topos estão mapeados nesta classe, o que se mostra contraditório ao se comparar com o mapeamento preexistente.

\section{Conclusões}

O mapeamento digital de solos, por meio da integração de atributos topográficos, demonstrou potencial para auxiliar na compreensão da relação solo-relevo e na predição, em escala regional, da distribuição das unidades de mapeamento em paisagens com relevos mais suaves, característicos do noroeste do estado do Paraná. O uso de ferramentas de SIG, bem como do método de regressões logísticas múltiplas multinominais, possibilitaram a integração dos atributos topográficos, na qual puderam representar espacialmente a distribuição dos Latossolos e dos Argissolos na área de estudo. Neste sentido, a escolha desses atributos topográficos específicos foi essencial para que o mapeamento fosse coerente, ao se comparar os resultados da predição com o mapeamento preexistente, pois deve-se conhecer suas potencialidades em relação a espacialização dos solos a serem preditos. Destaca-se o papel do atributo IPT que permitiu distinguir porções da vertente onde encontram-se Latossolos (topos e terços superiores) e Argissolos (terços médios e interiores).

A etapa de definição do tamanho do pixel para a geração do modelo digital do terreno (20 metros) foi fundamental para que os resultados obtidos fossem satisfatórios. Ressalta-se a importância de se ter uma base cartográfica corrigida, pois erros e ruídos comprometem a qualidade do mapeamento final, como curvas e pontos cotados com valores incoerentes ou até mesmo a rede hidrográfica. Nas regressões logísticas, a quantidade de pontos de controle utilizada foi essencial para que os modelos pudessem alcançar índices de qualidade aceitáveis. Os testes de validação mostraram que os pontos inseridos tiveram uma acurácia considerada satisfatória, contudo recomenda-se que haja sempre uma maior quantidade de pontos de controle, pois quanto mais informação tiver, melhores serão as análises da espacialização das unidades de mapeamento, principalmente quando as áreas apresentarem sistemas de transformação que, nos mapas convencionais, são muitas vezes incluídos como associações de solos pela dificuldade de definir os limites entres as classes. Sendo assim, o mapeamento preexistente foi fundamental na análise de verificação de qualidade.

Pela carência de mapas pedológicos em escala de detalhe no Brasil, o mapeamento digital de solos se mostra como uma ferramenta com grande potencial para auxiliar nos mapeamentos pedológicos, servindo de subsídio para atividades de planejamento ambiental, entre outras. Finalmente, este trabalho demonstrou que mesmo em regiões com predomínio de relevos pouco contrastados, é possível atingir resultados confiáveis no que se refere ao mapeamento digital de solos.

Contribuições dos Autores: Alexei Nowatzki (1) participou de todas as etapas de desenvolvimento desse trabalho, uma vez que o manuscrito apresentou parte dos resultados obtidos em seu doutorado. Leonardo José Cordeiro Santos (2) participou da concepção metodológica, escrita do artigo, revisão e supervisão da pesquisa. Todos os autores leram e concordaram com a versão publicada do manuscrito.

Financiamento: Esta pesquisa foi financiada pela CAPES (Coordenação de Aperfeiçoamento de Pessoal de Nível Superior) por meio de bolsa de doutorado.

Agradecimentos: À CAPES (Coordenação de Aperfeiçoamento de Pessoal de Nível Superior) e ao CNPq (Conselho Nacional de Desenvolvimento Científico e Tecnológico). À Milton Satoshi Matsushita por disponibilizar o material sobre o curso de mapeamento digital de solos com uso do QGIS e ao Instituto Paranaense de Assistência Técnica e Extensão Rural (Instituto EMATER). Por fim, ao professor e pesquisador da área de Pedometria Alessandro Samuel-Rosa da Universidade Tecnológica Federal do Paraná, Campus Santa Helena (UTFPR-SH) pelos esclarecimentos acerca do método das regressões logísticas aplicadas aos mapeamentos digitais de solos.

Conflito de Interesse: Os autores declaram não haver conflito de interesse. Os financiadores não tiveram interferência no desenvolvimento do estudo; na coleta, análise ou interpretação dos dados; na redação do manuscrito, ou na decisão de publicar os resultados. Este artigo é parte da tese de doutorado do primeiro autor, Alexei Nowatzki (1) desenvolvida sob orientação de Leonardo José Cordeiro Santos (2) e defendida em 2019 no Programa de Pós-graduação em Geografia da Universidade Federal do Paraná. 


\section{Referências}

1. BAILEY, N.; CLEMENTS, T.; LEE, J.T.; THOMPSON, S. Modelling soil series data to facilitate targeted habitat restoration: A polytomous logistic regression approach. Journal of Environmental Management. 67:395-407, 2003. DOI: 10.1016/s0301-4797(02)00227-x

2. BECKAUSER, M. C.; SILVEIRA, H. Caracterização da cobertura pedológica ao longo de uma topossequência situada no distrito do Sumaré em Paranavaí-PR. Geofronter, v. 6, n. 1, 2020.

3. BÖHNER, J.; SELIGE, T. Spatial prediction of soil atributes using terrain analysis and climate regionalisation. In: Böhner, J., McCloy, K.R., Strobl, J. [Eds.]: Göttinger Geogr. SAGA - Analyses and Modelling Applications. Abh, n. $115,2006$.

4. BOULET, R.; CHAUVEL, A.; HUMBEL, F. X.; LUCAS, Y. Analyse estructurale et cartographie en pedologie. I - Prise en compte l'organisation bidimensionalle de la couverture pédologique: les étude de toposéquenses et leurs principaux apport à la connaissance des sols. Cah. Orstom. Paris, França. Série Pédologie. v. XIX, n. 4. p. $309-322$. 1982

5. CHATTERJEE, S.; HADI, A. S. Regression analysis by example. 5.ed. New York, John Willey \& Sons, 375 p, 2006.

6. CHRISTOFOLETTI, A. Geomorfologia. 2. Ed. São Paulo, Editora Edgard Blucher, 2011. ISBN: 9788521201304

7. COELHO, F. F. Comparação de métodos de mapeamento digital de solos através de variáveis geomorfométricas e sistemas de informações geográficas. Porto Alegre, 2010, 80 f. Dissertação (Mestrado em Sensoriamento Remoto). Programa de pós-graduação em Sensoriamento Remoto. Centro estadual de pesquisas em Sensoriamento Remoto e Meteorologia. Universidade Federal do Rio Grande do Sul.

8. COELHO, F. F.; GIASSON, E. Métodos para mapeamento digital de solos com utilização de sistema de informação geográfica. Revista Ciência Rural, Santa Maria, v.40, n.10. outubro, 2010. DOI: 10.1590/S0103-84782010005000156

9. CUNHA, J. E.; CASTRO, S. S.; SALOMAO, F. X. T. Comportamento erosivo de um sistema pedológico de Umuarama, noroeste do estado do Paraná. Rev. Bras. Ciênc. Solo, Viçosa, v.23, n.4, pp. 943-951, 1999. DOI: 10.1590/S010006831999000400021

10. CUNHA, J. E.; NOBREGA, M. T.; CASTRO, S.S. Infiltração da água no solo no sistema pedológico Campus do Arenito, cidade gaúcha, noroeste do estado do Paraná. Rev. Bras. Ciênc. Solo, Viçosa, v.32, n.5, p. 1837-1848, 2008. DOI: 10.1590/S0100-06832008000500005

11. DALMOLIN, R. S. D.; TEN CATEN, A. Mapeamento Digital: nova abordagem em levantamento de solos. Investigación Agraria, v. 17, p. 77-86, 2015. DOI: 10.18004/investig.agrar.2015.diciembre.77-86

12. DE BIASI, Mário. A carta clinográfica: Os Métodos de Representação e sua Confecção. Revista do Departamento de Geografia, v. 6, p. 45-53, 1992. DOI: 10.7154/RDG.1992.0006.0004

13. DEBELLA-GILO, M.; ETZELMULLER, B. Spatial prediction of soil classes using digital terrain analysis and multinomial logistic regression modeling integrated in GIS: Examples from Vestfold County, Norway. Catena, v.77, p.8-18, 2009. DOI: 10.1016/j.catena.2008.12.001

14. FASOlO, P. J.; CARDOSO, A.; CARVAlHO, A. D.; HOCHMÜLlER, D.; RAUEN, M. D. J.; \& PÖTTER, R. (1988). Erosão: inventário de áreas críticas no Noroeste do Paraná. Curitiba, Instituto Agronômico do Paraná, 1988.

15. FERNANDES BARROS, O. M. Análise Estrutural e cartografia detalhada de solos em Marília, estado de São Paulo: ensaio metodológico. São Paulo, 146 f. Dissertação (Mestrado em Geografia) - FFLCH, Universidade de São Paulo, 1985.

16. FERNANDES, L. A.; COIMBRA, A. M. O Grupo Caiuá (Ks): revisão estratigráfica e contexto deposicional. Revista Brasileira de Geociências, v. 24, n. 3, p. 164-76, 1994.

17. FERNANDES, L. A.; COUTO, E. V.; SANTOS, L. J. C. Três Morrinhos, Terra Rica, PR Arenitos silicificados de dunas do Deserto Caiuá testemunham nível de superfície de aplainamento K-T. In: WINGE, M. et al (edit./org.). Sítios geológicos e paleontológicos do Brasil, vol. III. Brasília. Serviço Geológico do Brasil - CPRM v. III, p. 69-87, 2012.

18. FIGUEIREDO, S. R.; GIASSON, E.; TORNQUIST, C. G.; NASCIMENTO, P.C. Uso de regressões logísticas múltiplas para mapeamento digital de solos no planalto médio do RS. Rev. Bras. Ciênc. Solo, 32:2779-2785, 2008. DOI: 10.1590/S0100-06832008000700023

19. FUMIYA, M. H.; SANTOS, L. J. C.; MANGUEIRA, C. G. COUTO, E. V. Emprego do índice de concentração da rugosidade para a identificação de feições morfológicas associadas as crostas ferruginosas no Noroeste do Paraná. Revista Brasileira de Geomorfologia.v.17, n.3, p.465-480, 2016. DOI: 10.20502/rbg.v17i3.742

20. GIASSON, E., CLARKE, R.T., INDA JUNIOR, A.V., MERTEN, G.H., TORNQUIST, C.G. Digital soil mapping using multiple logistic regression on terrain paramenters in Southern Brazil. Sci. agric. (Piracicaba, Braz.), Piracicaba, v. 63, n. 3, p. 262-268, 2006. DOI: 10.1590/S0103-90162006000300008 
21. GIASSON, E.; FIGUEIREDO, S.R.; TORNQUIST, C.G.; CLARKE, R.T. Digital soil mapping using logistic regression on terrain parameters for several ecological regions in southern Brazil. In: HARTEMINK, A. E.; MCBRATNEY, A.; MENDONÇA SANTOS, M. DE L. (Ed.). Digital soil mapping with limited data. New York: Springer-Verlag, p.225$232,2008$.

22. HENGL, T.; TOOMANIAN, N.; REUTER, H.I. \& MALAKOUTI, M.J. Methods to interpolate soil categorical variables from profile observations: Lessons from Iran. Geoderma, 140:417-427, 2007. DOI: 10.1016/j.geoderma.2007.04.022

23. HUNG, M. N. W. B.; SIEFERT, C. A. C.; SANTOS, I. Simulação hidrogeomorfológica da dinâmica das áreas saturadas da bacia do rio corredeiras, Rio Negrinho -SC. RA'E GA: o Espaço Geográfico em Análise. Curitiba, v.41 Temático de Geomorfologia, p. 208-227, 2017. DOI: 10.5380/raega.v41i0.52423

24. INSTITUTO BRASILEIRO DE GEOGRAFIA E ESTATÍSTICA (IBGE). Coordenação de Recursos Naturais e Estudos Ambientais. Manual técnico de pedologia. 3. ed. Rio de Janeiro, 430 p. 2015.

25. INSTITUTO BRASILEIRO DE GEOGRAFIA E ESTATÍSTICA (IBGE). Manual técnico de geomorfologia. 2. Ed. Rio de Janeiro: IBGE, 2009.

26. INSTITUTO BRASILEIRO DE GEOGRAFIA E ESTATÍSTICA (IBGE). Portal BDiA. Banco de Dados de Informações Ambientais. Rio de Janeiro. 2018. Disponível em: < https://bdiaweb.ibge.gov.br/\#/consulta/pedologia> Acesso em: 15 dez. 2018.

27. KEMPEN, B.; BRUS, D. J.; HEUVELINK, G. B. M.; STOORVOGEL, J. J. Updating the 1:50.000 Dutch soil map using legacy soil data: A multinomial logistic regression approach. Geoderma, v.125, p.311-326, 2009. DOI: 10.1016/j.geoderma.2009.04.023

28. LAGACHERIE, P. Digital Soil Mapping: A State of art. In.: HARTEMINK, A.E.; McBATNEY, A.; MENDONÇASANTOS, M. DE L. (Ed.), Digital Soil Mapping with Limited Data. New York: Springer, p.3-14, 2008. ISBN: 978-14020-8592-5

29. LAGACHERIE, P.; VOLTZ, M. Predicting soil properties over a region using sample information from a mapped reference area and digital elevation data: a conditional probability approach. Geoderma. v.97, p. 187-208, 2000. DOI: 10.1016/S0016-7061(00)00038-0

30. LARACH, J. O. I.; CARDOSO, A.; CARVALHO, A. P. de; HOCHMÜLLER, D. P.; MARTINS, J. S.; RAUEN, M. de J.; FASOLO, P. J.; PÖTTER, R. O. Levantamento de reconhecimento dos solos do Estado do Paraná. Londrina: IAPAR; Curitiba: EMBRAPA-SNLCS, Vol. 2t, 1984.

31. LIMA, L. A. S.; NEUMANN, M. R.B.; REATTO, A.; ROIG, H. L. Mapeamento de Solos: do tradicional ao digital. Planaltina, DF: Embrapa Cerrados, Documentos M386, 2013.

32. MAACK, R. Geografia física do Estado do Paraná. 2ª ed. Rio de Janeiro: J. Olympio, 450 p, 1981.

33. McBRATNEY, A. B.; MENDONÇA-SANTOS, M. L.; MINASNY, B. On digital soil mapping. Geoderma, v. 117, p. 352, 2003. DOI: 10.1016/S0016-7061(03)00223-4

34. MINEROPAR (MINERAIS DO PARANÁ S/A). Atlas geológico do Estado do Paraná. 2001. Disponível em: <http://www.mineropar.pr.gov.br/arquivos/File/MapasPDF/atlasgeo.pdf >. Acesso em: 12 set. 2018.

35. MOORE, I. D.; GESSLER, P. E.; NIELSEN, G. A.; PETERSON, G. A. Soil attribute prediction using terrain analysis. Soil Science Society American Journal. v. 57, p. 443-452, 1993. DOI: 10.2136/sssaj1993.03615995005700020026x

36. MOURÃO-JUNIOR, C.A. Bioestatística: armadilhas e como evitá-las. Boletim do Centro da Biologia da Reprodução (UFJF), v. 26, p. 73-76, 2007.

37. NAKASHIMA, P. Sistemas pedológicos da região noroeste do Estado do Paraná: distribuição e subsídios para o controle da erosão. São Paulo, Tese (Doutorado em Geografia Física) Faculdade de Filosofia, Letras e Ciências Humanas, Universidade de São Paulo, 1999.

38. NASCIMENTO, F. A. F.; ROCHA, R. T. O.; BRAGATO, R. D.; MATSUSHITA, M. S.; BERTOL, O. J. Curso de Mapeamento Digital de Solos com uso do QGIS. Curitiba: Instituto Emater, 2017.

39. NOWATZKI, A.; OLIVEIRA, J. G.; HUNG, M. N. W. B.; SANTOS, L. J. C. Emprego da pedometria na identificação e delimitação dos solos localizados na planície fluvial do baixo curso da bacia hidrográfica do rio Ivaí (noroeste do Paraná). Revista de Geografia (Recife), v. 35, p. 145-161, 2018. DOI: 10.51359/2238-6211.2018.238212

40. NOWATZKI, A.; SANTOS, L. J. C. Mapeamento preliminar de solos por pedometria com base em atributos topográficos da bacia hidrográfica do rio Pequeno-PR. RA'E GA: o Espaço Geográfico em Análise, v. 32, p. 185-211, 2014. DOI: 10.5380/raega.v32i0.33769

41. RILEY, S. J.; DeGLORIA, S. D.; ELLIOT, R. A terrain ruggedness index that quantifies topographic heterogeneity. International Journal of Sciences. n. 1-4, v.5, 1999. 
42. RÓŻYCKA, M.; MIGOŃ, P.; MICHNIEWICZ, A. Topographic Wetness Index and Terrain Ruggedness Index in geomorphic characterisation of landslide terrains, on examples from the Sudetes, SW Poland. Zeitschrift Für Geomorphologie, Supplementary Issues, Schweizerbart. [s.1.], p.1-20, 2016. DOI: 10.1127/zfg_suppl/2016/0328

43. SAMPAIO, T. V. M.; AUSGUSTIN, C. H. R. R. Índice de Concentração da Rugosidade: uma nova proposta metodológica para o mapeamento e quantificação da dissecação do relevo como subsídio a cartografia geomorfológica. Revista Brasileira de Geomorfologia, v.15(1). p. 47-60, 2014. DOI: 10.20502/rbg.v15i1.376

44. SAMPAIO, T.V.M. Parâmetros morfométricos para melhoria da acurácia do mapeamento da rede de drenagem uma proposta baseada na análise da bacia hidrográfica do rio Benevente - ES. Tese (Doutorado). Instituto de Geociências, Universidade Federal de Minas Gerais, Belo Horizonte, 2008.

45. SANTOS, L. J. C.; FIORI, C. O.; CANALI, N. E.; FIORI, A. P.; SILVEIRA, C. T.; SILVA, J. M. F; ROSS, J. S. Mapeamento Geomorfológico do Estado do Paraná. Revista Brasileira de Geomorfologia. Ano 7, n 2, 2006 . DOI: 10.20502/rbg.v7i2.74

46. SANTOS, M. L.; MORAIS, E. S.; SILVEIRA, H.; ALVES, F.C. Estudo do escoamento superficial na bacia hidrográfica do rio Ivaí, Paraná, Brasil. Revista Brasileira de Geomorfologia, v. 14, n. 3, 2013. DOI: 10.20502/rbg.v14i3.286

47. SANTOS, M. O. Análise de estabilidade de vertentes por meio da utilização dos métodos de Feições Mínimas do relevo e Fator de Segurança. São Paulo. 119 p. Dissertação (Mestrado em Geografia Física) - Departamento de Geografia da FFLCH, Universidade de São Paulo. 2015.

48. SANTOS, H. G. dos; JACOMINE, P. K. T.; ANJOS, L. H. C. dos; OLIVEIRA, V. A. de; LUMBRERAS, J. F.; COELHO, M. R.; ALMEIDA, J. A. de; ARAUJO FILHO, J. C. de; OLIVEIRA, J. B. de; CUNHA, T. J. F. Sistema Brasileiro de Classificação de Solos. 5. ed. rev. e ampl. Brasília, DF: Embrapa, 2018.

49. SILVA, J. M. F.; OKA-FIORI, C.; SILVEIRA, C. T. Índice de Diversidade de Formas de Relevo do Setor Norte da Apa da Serra da Esperança (PR) com Emprego de Técnica de Classificação Geomorfométrica. Revista do Departamento de Geografia USP, Volume Especial - Eixo 6, p.112-123, 2017. DOI: 10.11606/rdg.v0ispe.132712

50. SILVA, L.M.; FIDALSKI J.; BERTOL, O. J. Disponibilidade de água do solo em uma catena característica do arenito no noroeste do Paraná. In: Congresso Brasileiro de Ciência do Solo, 33. Uberlândia, 2011. Anais. Sociedade Brasileira de Ciência do Solo, Viçosa, 4p. 1, 2011.

51. SILVEIRA, C. T. Análise digital do relevo na predição de unidades preliminares de mapeamento de solos: Integração de atributos topográficos em Sistemas de Informações Geográficas e redes neurais artificiais. Curitiba, 2010, 153 f. Tese (Doutorado em Geografia). Departamento de Geografia, Setor de Ciências da Terra, Universidade Federal do Paraná. 2010.

52. SILVEIRA, C. T. OKA-FIORI, C.; SANTOS, L. J. C.; SIRTOLI, A. V.; SILVA, C. R.; BOTELHO, M. F. Soil prediction using artificial neural networks and topographic attributes. Geoderma. Vol. 172. 165-172, 2013. DOI: 10.1016/j.geoderma.2012.11.016

53. SIRTOLI, A. E.; SIlveIRA, C. T.; MONTOVANI, L. E.; SIRTOLI, A. R. A.; OKA FIORI, C. Atributos do relevo derivados de modelo digital de elevação e suas relações com solos. Scientia agraria, v.9, n.3, p.317-329, 2008. DOI: 10.5380/rsa.v9i3.11517

54. SIRTOLI, A. V. Mapeamento de Solos Com Auxílio da Geologia, Atributos do Terreno e Índices Espectrais Integrados Por Redes Neurais Artificiais. Universidade Federal do Paraná. Curitiba, 2008. 114f. Tese (Doutorado em Geologia Ambiental) - Setor de Ciências da Terra, Universidade Federal do Paraná. 2008.

55. SOUZA, E. Mapeamento digital de solos e modelagem da recarga hídrica na Bacia do Rio Doce, Minas Gerais. 2013. 169 f. Tese (Doutorado em Fertilidade do solo e nutrição de plantas; Gênese, Morfologia e Classificação, Mineralogia, Química,) - Universidade Federal de Viçosa, Viçosa, 2013.

56. SOUZA, E.; FERNANDES FILHO, E. I.; SCHAEFER, C. E. G. R.; BATJES, N. H.; SANTOS, G. R.; PONTES, L. M. Pedotransfer functions to estimate bulk density from soil properties and environmental covariates: Rio Doce basin. Scientia Agricola, v. 73, p. 525-534, 2016. DOI: 10.1590/0103-9016-2015-0485

57. STRAHLER, A.N. Hypsometric analysis of erosional topography. Geol. Soc. America Bulletin, 63, 1952, p. 1117-1142.

58. TEN CATEN, A. Aplicação de componentes principais e regressões logísticas múltiplas em sistema de informações geográficas para a predição e o mapeamento digital de solos. Santa Maria, 2008, 120 f. Dissertação (Mestrado em Centro de Ciências Rurais) Programa de Pós-Graduação em Ciência do Solo. Universidade Federal de Santa Maria, 2008.

59. TEN CATEN, A.; DALMOLIN, R. S. D.; PEDRON, F. A.; MENDONCA-SANTOS, M. L. Regressões Logísticas Múltiplas: fatores que influenciam sua aplicação na predição de classes de solos. Rev. Bras. Ciênc. Solo [online], vol.35, n.1, pp.53-62. 2011. DOI: 10.1590/S0100-06832011000100005 
60. TEN CATEN, A; DALMOLIN, R. S. D.; PEDRON, F. A.; SANTOS, M. L. M. Componentes principais como preditores no mapeamento digital de classes de solos. Cienc. Rural, Santa Maria, v. 41, n. 7, p. 1170-1176, 2011b. DOI: 10.1590/S0103-84782011000700011

61. TESKE, R.; GIASSON, E.; BAGATINI, T. Produção de um mapa pedológico associando técnicas comuns aos mapeamentos digitais de solos com delineamento manual de unidades de mapeamento. Rev. Bras. Ciênc. Solo, Viçosa, v. 39, n. 4, p. 950-959, 2015. DOI: 10.1590/01000683rbcs20140285

62. VALERIANO, M. M.; CARVALHO JÚNIOR, O, A. Geoprocessamento de modelos digitais de elevação para mapeamento da curvatura horizontal em microbacias. Revista Brasileira de Geomorfologia, v 4, n.1, p.17-29, 2003. DOI: $10.20502 /$ rbg.v4i1.17

63. VENABLES, W. N.; RIPLEY, B. D. Modern Applied Statistics with S. Fourth edition. Springer, 2002. ISBN-10: 0387954570; ISBN-13: 978-0387954578

64. WEISS, A. Topographic Position and Landforms Analysis. Poster presentation, ESRI User Conference, San Diego, CA, 2001.

65. WILSON, J. P.; GALLANT, J. C. (eds.). Terrain analysis: principles and applications. New York: John Wiley \& Sons, p.1-27, 2000. ISBN: 978-0-471-32188-0

Esta obra está licenciada com uma Licença Creative Commons Atribuição 4.0 Internacional (http://creativecommons.org/licenses/by/4.0/) - CC BY. Esta licença permite que outros distribuam, remixem, adaptem e criem a partir do seu trabalho, mesmo para fins comerciais, desde que lhe atribuam o devido crédito pela criação original. 